\title{
PERENCANAAN E-PROCUREMENT DALAM PENGADAAN MATERIAL PESAWAT
}

\author{
Dian Permata Sari \\ Pendidikan Sistem dan Teknologi Informasi, Universitas Pendidikan Indonesia \\ dianpermatasari@upi.edu
}

\begin{abstract}
With frequent delays in booking aircraft materials carried out in several countries, including: Germany, the United States and France which still use E-Mail in their orders. So the researcher built an E-procurement information system in saturating orders made like a simple tender system. The methodology used in building this E-Procurement information system uses the waterfall methodology as the engineering system stage, namely: Analysis, Designing, cooding, testing and implementation of the system. Whereas the model or tool used in this analytical designer is using UML (Unified Model Language), so the expectation of making this E-Procurement information system is to assist the procurement of aircraft materials in meeting the needs of the procurement of materials in warehouses with good material quality cheap and non-miss communication on orders.
\end{abstract}

Key Word : E-Procurement, booking for aircraft materials.

\section{PENDAHULUAN}

Dalam memenuhi kebutuhan aktivitas yang cukup tinggi bagi perusahaaan serta penggunaan teknologi informasi yang sangat praktis, sehingga sangat membantu para penggunanya dalam melakukan aktivitas pekerjaan dengan begitu mudah pada saat ini. Penggunaan teknologi yang berkembang pesat pun di barengi dengan adanya tingkat akses internet yang mendukung dalam penggunaan teknologi di Indonesia saaat ini, dalam pekerjaan peruhaan dengan sistem kerja yang tinggi dalam kebutuhan informasi yang cepat, akurat serta relevan bukanlah suatu hal yang sulit untuk dilakukan.

Dengan Adanya beberapa kendala dalam salah satu proses bisnis pemesanan material pewawat disini, yaitu sering terjadi keterlambatan dalam penerimaan $e$-mail atau masuknya e-mail berisi data order material pesawat ke spam ke berbagai negara baik dari pihak perusahaan maupun supplier. Selain itu terdapat kendala lain yang dihadapi, yaitu hasil data transaksi yang dirasakan masih kurang sesuai dari harga pemesanan yang ditawarkan sebelumnya oleh perusahaan-perusahaan tersebut

Salah satu penerapan aplikasi yang ditawarkan adalah dibuatkannya sistem informasi khusus dalam melakukan pemesanan material pesawat di perusahaan tersebut. Sehingga, sebagai media atau sarana yang membantu berbagai aktivitas pengolahan data untuk menghasilkan informasi secara menyeluruh, yang nantinya dapat dilihat dan digunakan semua pihak yang berkepentingan. Kemudian, dengan keberadaan fungsi sistem informasi pemesanan material pesawat ini juga dapat digunakan untuk menghubungkan pelayanan terhadap perusahaan-perusahaan lain sebagai bentuk pengadaan pemesanan material pesawat, melakukan tender dan meningkatkan citra sebuah perusahaan agar terus dapat bertahan dan menjadi yang terdepan dalam memenuhi kebutuhannya.

\section{KAJIAN PUSTAKA \\ Perancangan}

Dari Gustafson: 
"Design is the process of applying various techniques and principles for the purpose of defining a device, a prosess,or a system in sufficient detail to permit its physical realization".

Ini berarti bahwa dalam proses perencanaan dapat menggunakan berbagai jenis teknik demi mewujudkan tujuan yang ingin dicapai. Di dalam proses perencanaan harus didefinisikan segala jenis peralatan, proses yang akan terjadi serta keterbatasan dalam implementasi yang akan dilakukan. Sebuah perancangan merupakan aktivitas yang mengusulkan sebuah solusi teknis sehingga nantinya akan dapat memenuhi hasil dari analisa kebutuhan sistem [1].

\section{E-procurement}

Beberapa definisi oleh Davila, Tony, Mahendra Gupta, dan Richard Palmer dalam jurnal "Moving Procurement Systems to The Internet" (2003) menyebutkan e-procurement :Teknologi yang dirancang untuk memfasilitasi pengadaan barang melalui internet, Manajemen seluruh aktivitas pengadaan secara elektronik, Aspek-aspek fungsi pengadaan yang didukung oleh bermacam-macam bentuk komunikasi secara elektronik [2].

\section{Internet}

Internet adalah suatu jaringan komputer yang sangat besar, terdiri dari jutaan perangkat komputer yang terhubung melalui suatu protocol tertentu untuk pertukaran informasi antar komputer tersebut. Semua komputer terhubung di internet melakukan pertukaran informasi melalui protocol yang sama yaitu dengan TCP/IP (Transmission Control Protocol/Internet Protocol) [3]. Internet menyediakan akses untuk layanan telekomunikasi dari sumber daya informasi untuk jutaan pemakainya yang tersebar di seluruh dunia.

Pemanfaatan internet semakin meluas seiring dengan banyaknya bisnis, organisasi, komputer, dan jaringan-jaringan yang tergabung kedalam web global dengan menggunakan jaringan ini. Sebuah organisasi dapat melakukan pertukaran informasi internal maupun informasi eksternal dengan organisasi lain. Secara khusus, internet tidak memiliki sistem komputer pusat. Pesan yang dikirim memiliki kode khusus yang akan memudahkan server internet untuk melakukan pengiriman sesuai tujuannya.

Internet atau internasional network merupakan rangkaian-rangkaian jaringan terbesar di dunia dimana semua jaringan yang berada pada semua organisasi dihubungkan dengan suatu jaringan terbesar sehingga dapat saling berkomunikasi. Dalam jaringan tersebut mungkin melibatkan LAN,MAN,dan WAN yang ada di seluruh dunia.

Untuk dapat menggunakan layanan internet, organisasi atau perusahaan harus terhubung dengan jaringan internet atau dengan menjadi pelanggan ISP (Internet Server Provider). ISP adalah organisasi komersial yang bergerak dalam penyediaan jasa akses internet.

\section{Objek Penelitian}

Tempat yang dijadikan penulis sebagai objek penelitian yakni sebuah bidang jasa procurement untuk pemesanan material pembuatan pesawat.

\section{METODELOGI PENELITIAN}

Metode suatu kerja untuk melakukan suatu tindakan atau suatu kerangka berpikir dengan menyusun gagasan yang beraturan, berarah dan berkonteks dengan maksud dan tujuan. Metode pendekatan analisis dan pemrograman notasi yang berorientasi objek, sebagai metode untuk mencari pemecahan permasalahan dalam pemesanan material pesawat 
diberbagai negara. Sehingga dapat mendapatkan solusi dan pemecahan masalahnya dengan didasari dari data-data yang telah ada.

\title{
Jenis Dan Pengumpulan Data
}

Adapun langkah-langkah yang digunakan untuk mendapatkan informasi ini, penulis mencoba untuk menerapkan teori-teori yang didapat selama perkuliahan dengan menggunakan teknik pengumpulan data primer dan data Sekunder. Data primer berasal dari sumber pertama diantaranya: studi lapangan dengan melakukan pengamatan (observasi), wawancara (interview) dan data [4]. Sedangkan data sekunder: pengumpulan data dengan cara mempelajari dan menganalisis buku-buku, karangan-karangan, literaturliteratur yang berkaitan dengan permasalahan yang diteliti.

\section{Metode Pengembangan Sistem}

Metode pengembangan sistem yang digunakan adalah dengan menggunakan metode prototipe. Prototipe paradigma dimulai dengan mengumpulkan kebutuhan, yaitu mendengarkan pelanggan, membangun dan memperbaiki prototype dan melakukan uji coba prototype [5].

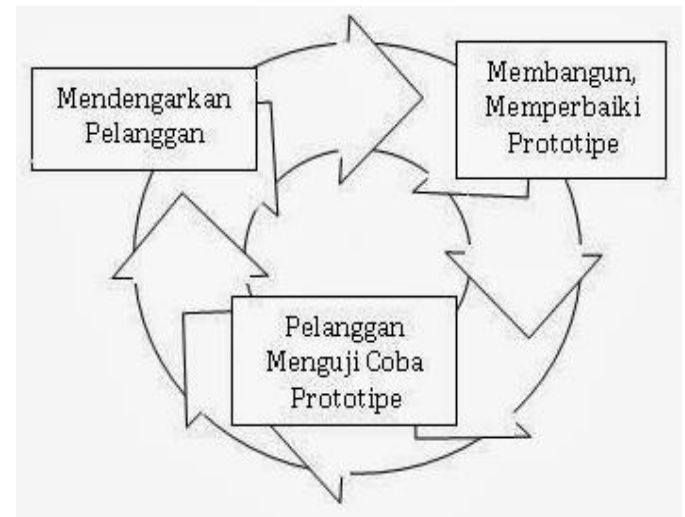

Gambar 1 Prototype Paradigma

Sumber (Rekayasa Perangkat Lunak, Roger S.Pressman, Ph.D). 2002 : 40)

\begin{abstract}
Alat Bantu Analisis
Pembangunan sistem informasi dengan berorientasi objek merupakan suatu perancangan yang berbeda dengan yang berorientasi data. Namun secara konteks perancangan ini digunakan untuk membangun sistem informasi sesuai kebutuhan dari pemakai (user) sistem informasi. Menurut Martin Fowler (2004:1) "Unified Modeling Language (UML) adalah keluarga notasi grafis yang didukung oleh meta-model tunggal, yang membantu pedeskripsian dan desain system perangkat lunak, khususnya system yang dibangun menggunnakan pemograman berorientasi objek (OO)" [6]. UML sendiri telah menyediakan alat-alat bantu berupa diagram visual yang menggambarkan berbagai aspek yang ada di dalam sistem.

\section{HASIL DAN PEMBAHASAN}

a. Evaluasi Sistem Berjalan

Berikut evaluasi sistem yang berjalan saat melakukan pemesanan material pesawat ke berbagai negara.
\end{abstract}

\section{b. Sistem yang diusulkan}


Tabel 1. Sistem yang berjalan

\begin{tabular}{|c|l|l|l|}
\hline No & \multicolumn{1}{|c|}{ Permasalahan } & \multicolumn{1}{c|}{ Devisi } & \multicolumn{1}{c|}{ Pemecahan } \\
\hline 1 & $\begin{array}{l}\text { Belum adanya pengembangan } \\
\text { website untuk proses } \\
\text { procurement atau pemesanan } \\
\text { material pesawat terhadap } \\
\text { supplier di beberapa negara, } \\
\text { pemesanan yang masih } \\
\text { menggunakan E-mail yahoo } \\
\text { dirasa kurang efisien dalam } \\
\text { penggunaannya. }\end{array}$ & $\begin{array}{l}\text { Bag. } \\
\text { Procurement } \\
\text { dan Supplier }\end{array}$ & $\begin{array}{l}\text { Membangun sebuah website } \\
\text { sebagai jembatan atau } \\
\text { penghubung secara formal } \\
\text { perusahaan terhadap suplier. }\end{array}$ \\
\hline 2 & $\begin{array}{l}\text { Informasi transaksi yang di } \\
\text { dapat dirasakan kurang efektif } \\
\text { sehingga sering terjadinya } \\
\text { manipulasi data. }\end{array}$ & $\begin{array}{l}\text { Bag. } \\
\text { Procurement } \\
\text { dan Supplier }\end{array}$ & $\begin{array}{l}\text { Perlunya adanya simpanan } \\
\text { berupa database sebagai } \\
\text { penampilan data simpanan } \\
\text { transaksi. }\end{array}$ \\
\hline
\end{tabular}

Setelah melihat tabel diatas maka perangkat lunak yang akan dibangun, yaitu perancangan E-procurement yang merupakan sebuah aplikasi untuk melakukan pemesanan material pesawat ke beberapa negara khususnya Amerika Srikat $(A S)$, German dan Prancis untuk memberikan dalam memberikan informasi kepada supplier tentang pengadaan kebutuhankebutuhan material pesawat.

Tabel 2. Hak dan Otorisasi User

\begin{tabular}{|l|l|ll|}
\hline Kategori Pengguna & \multicolumn{1}{|c|}{ Tugas } & \multicolumn{1}{c|}{ Hak } \\
\hline Bag Procurement & $\begin{array}{l}\text { Mengelola E- } \\
\text { Procurement }\end{array}$ & 1. $\begin{array}{l}\text { Mengadakan kebutuhan material } \\
\text { pesawat pada supplier } \\
\text { 2. Menyeleksi supplier berdasarkan LSQ } \\
\text { (List Supplier Question) }\end{array}$ \\
\hline Supplier & $\begin{array}{l}\text { Melakukan } \\
\text { pendaftaran, } \\
\text { melakukan } \\
\text { penawaran } \\
\text { material }\end{array}$ & $\begin{array}{l}\text { Mendapatkan informasi pengadaan } \\
\text { material yang diadakan oleh perusahaan }\end{array}$ \\
\hline
\end{tabular}


Dibawah ini merupakan pemodelan usecase yang diusulkan (lihat gambar 2):

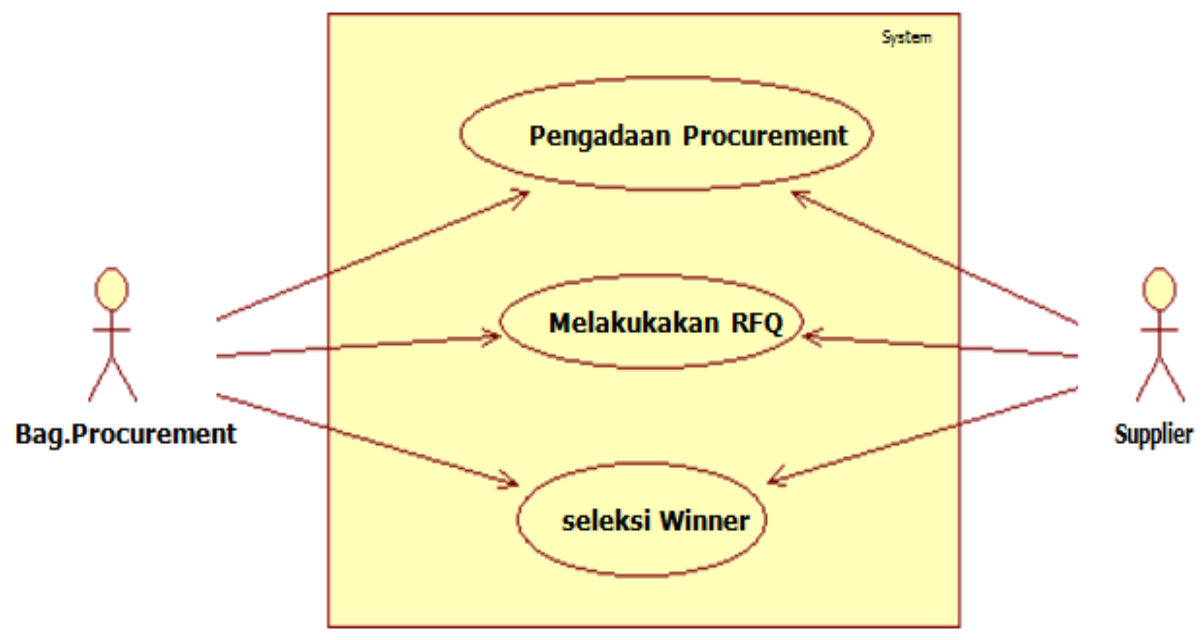

Gambar 2 Usecase yang diusulkan

1. Skenario usecase pengadaan procurement

Tabel 3. Skenario pengadaan procurement

\begin{tabular}{lll}
\hline Nama & $:$ & Pengadaan Procurement \\
Usecase & & \\
\hline Actor & $:$ & Bag. Procurement \\
Type & $:$ & Primary Key \\
Tujuan & $:$ & Menampilkan jenis pengadaan material yang diadakam oleh \\
& perusahaan \\
Deskripsi & $:$ & User masuk ke situs procurement. User harus login terlebih \\
& dahulu dan memilih beberapa menu yang tersedia. Memilih \\
& menu material adalah langkah pertama jika jenis material yang \\
& akan diadakan belum ada. Jika sudah ada, admin bisa menginput \\
& field berikutnya dan mengupdate procurement sebagai \\
& pengadaan material pesawat oleh perusahaan. Langkah \\
& berikutnya yaitu memilih supplier sebagai supplier yang telah \\
& ditunjuk dalam pengadaan penawaran material kepada \\
& perusahaan.
\end{tabular}

2. Skenario usecase melakukan RFQ (Request For Quation)

Tabel 4. Skenario melakukan RFQ

\begin{tabular}{lll}
\hline Nama & $:$ & Melakukan RFQ \\
Usecase & & \\
\hline Actor & $:$ & Supplier \\
Type & $:$ & Secondary \\
Tujuan & $:$ & Menampilkan form pengajuan penawaran material kepada \\
& pihak perusahaan \\
Deskripsi & $:$ & $\begin{array}{l}\text { User masuk ke situs procurement. User harus login terlebih } \\
\text { dahulu untuk dapat melihat pengadaan sebagai supplier yang } \\
\end{array}$ \\
& telah di tunjuk perusahaan dan mengajukan penawaran \\
\hline
\end{tabular}


material pesawat yang sedang diadakan oleh perusahaan.

3. Skenario usecase seleksi winner

Tabel 5. Sekenario seleksi winner

\begin{tabular}{lrl}
\hline Nama & $:$ & Seleksi Winner \\
Usecase & & \\
\hline Actor & $:$ & Bag. Procurement \\
Type & $:$ & Primary \\
Tujuan & $:$ & Menampilkan form seleksi supplier untuk admin \\
Deskripsi & $:$ & User masuk ke situs procurement. User harus login terlebih \\
& dahulu untuk memilih pemenang atau winner. Dalam seleksi \\
& $\begin{array}{l}\text { supplier di sesuaikan berdasarkan LSQ berdasarkan } \\
\text { pengajuan penawaran supplier pada perusahaan dan data dari } \\
\text { beberapa pemenang procurement dapat dilihat atau dicetak } \\
\text { berdasarkan priodik jika diperlukan. }\end{array}$ \\
&
\end{tabular}

\section{c. Implementasi sistem}

Berikut adalah beberapa interface system informasi E-Procurement untuk pemesanan material pesawat .

1. Halaman utama E-procurement dalam pengadaan material pesawat

Pada halaman utama E-Procurement berisisi tentang profil perusahaan, sebagai perusahaan yang bergerak pada pembuatan pesawat baik bagi dalam negeri dan luar negeri.

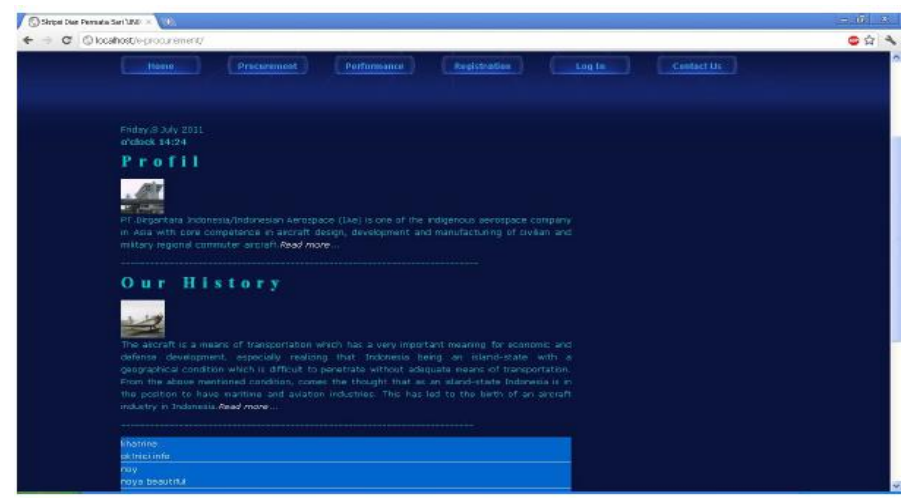

Gambar 3 Halaman Utama

2. Halaman Login

Halaman login adalah halaman bagi anggota yang terdaftar dan di Acc oleh perusahaan untuk mengikuti kegiatan E-Procurement material pesawat. 


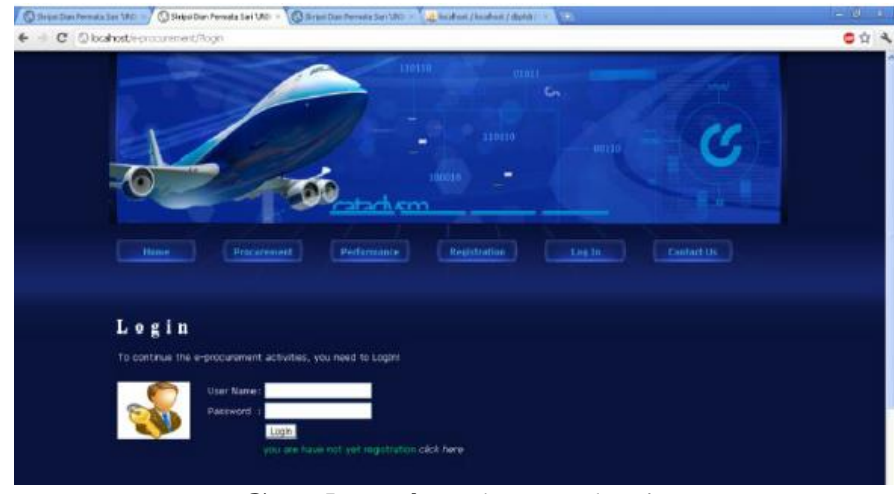

3. Halaman Registrasi

Gambar 4 Halaman login

Halaman regestrasi merupakan isi data anggota bagi yang belum terdaftar. Dan akan dapat login, setelah di acc oleh pihak perusahaan.

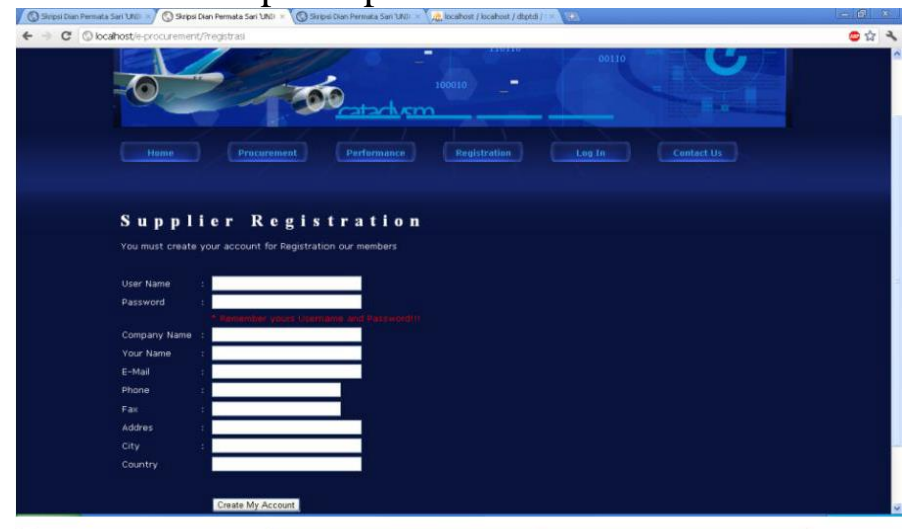

Gambar 5 Halaman registrasi

4. Halaman Pengadaan E-Procurement pengadaan material pesawat

Halaman E-procurement merupakan merupakan halaman pengumuman jika kemungkinan adanya kebutuhan material oleh perusahaan.

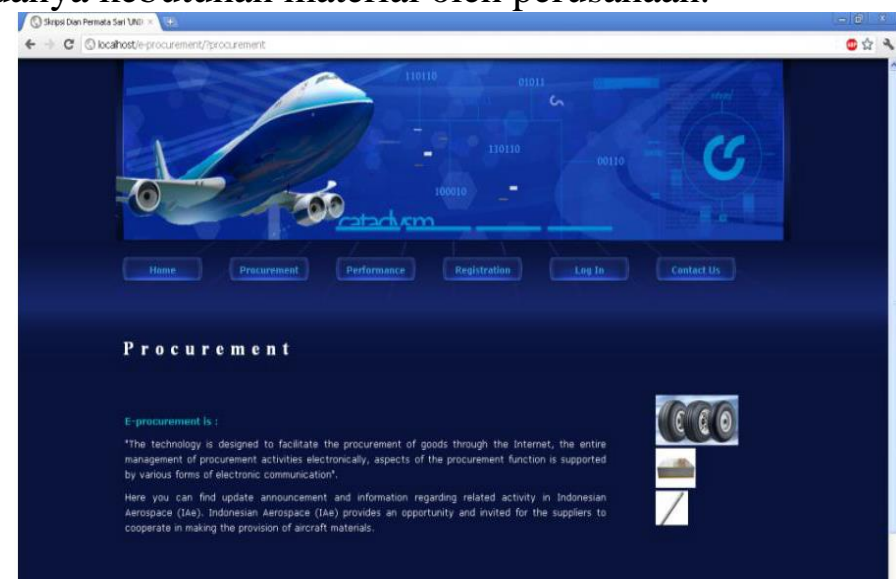

Gambar 6 Halaman E-Procurement

5. Halaman kebutuhan material pesawat oleh perusahaan

Halaman ini merupakan halaman untuk pihak perusahaan untuk melakukan pengumuman kebutuhan material pesawat, yang kemudianakan terbit dihalaman EProcurement. 
6. Halaman RFQ

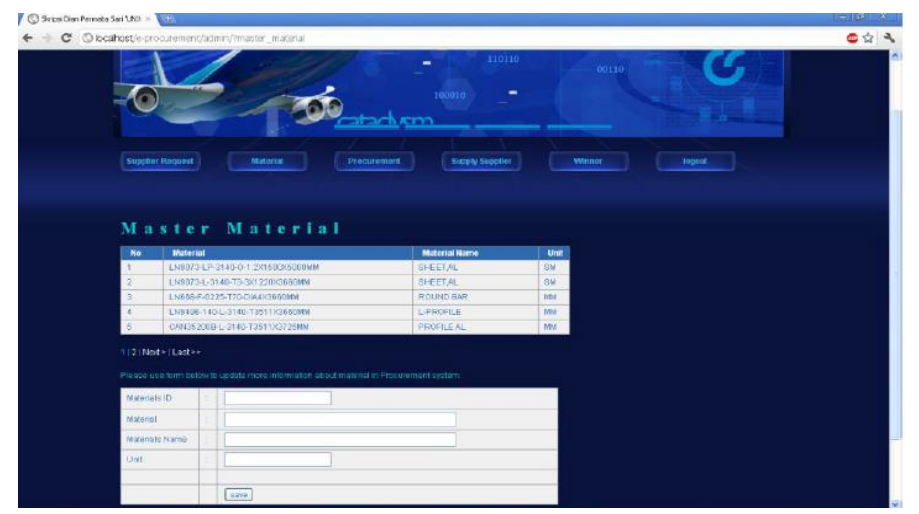

Gambar 7 Halaman Kebutuhan Material

Halaman RFQ (Request For Quation) merupakan halaman yang dapat di akses oleh anggota. Pada halaman ini anggota dapat melakukan penawaran harga dan kesediaan pengiriman barang dari Negara asal hingga sampai di pada perusahaan.

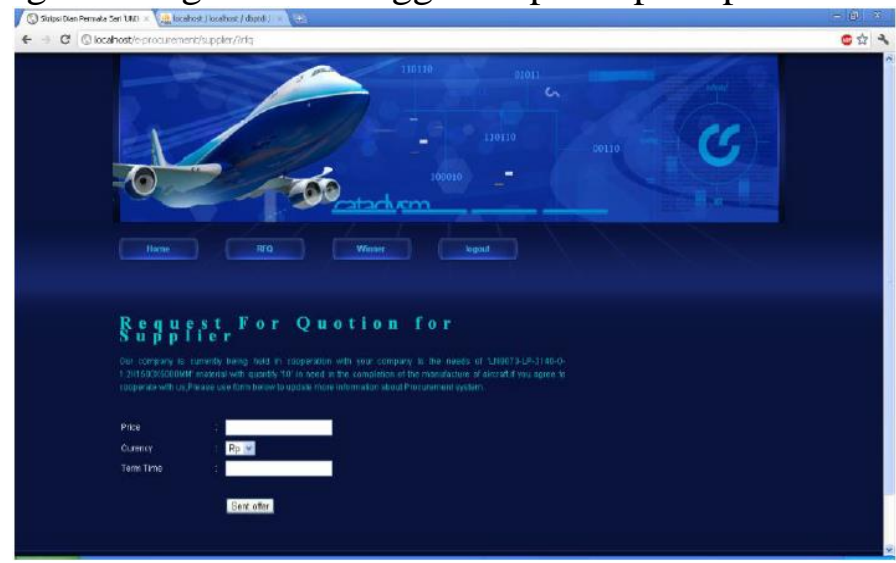

Gambar 8 Halaman RFQ

7. Halaman List ketersediaan material pesawat supplier

Pada halaman list ketersediaan material pesawat hanya dapat dilihat oleh pihak perusahaan, atau pihak perusahaan dapat melihat Negara mana saja yang mengajukan, melihat penawaran harga dan kesediaan dalam pengiriman material.

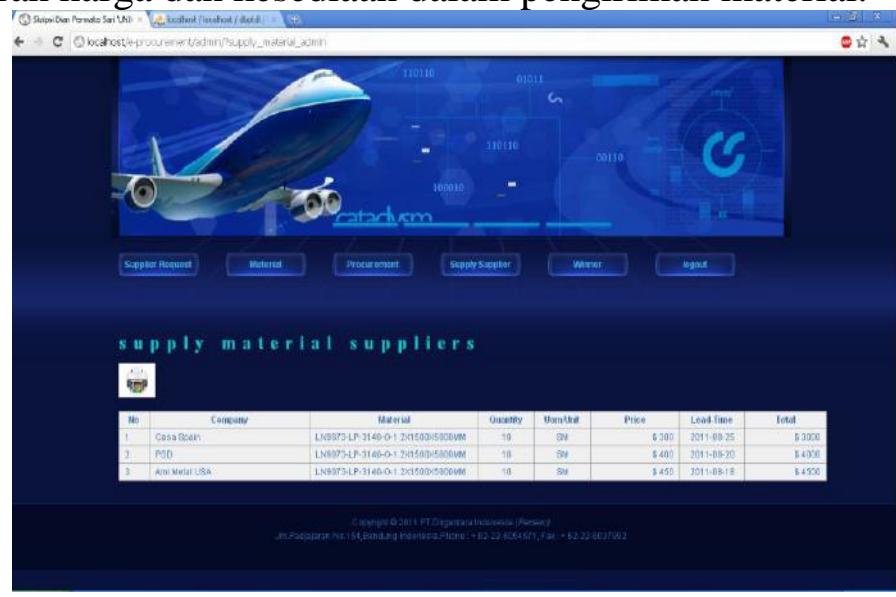

Gambar 9 List ketersediaan material pesawat

8. Halaman Penentuan winner oleh admin 
Halaman Penentuan winner, merupakan halaman yang hanya dapat diakses oleh pihak perusahaan dan menentukan pemenang yang telah memenuhi persyaratan dari kebutuhan material pesawat.

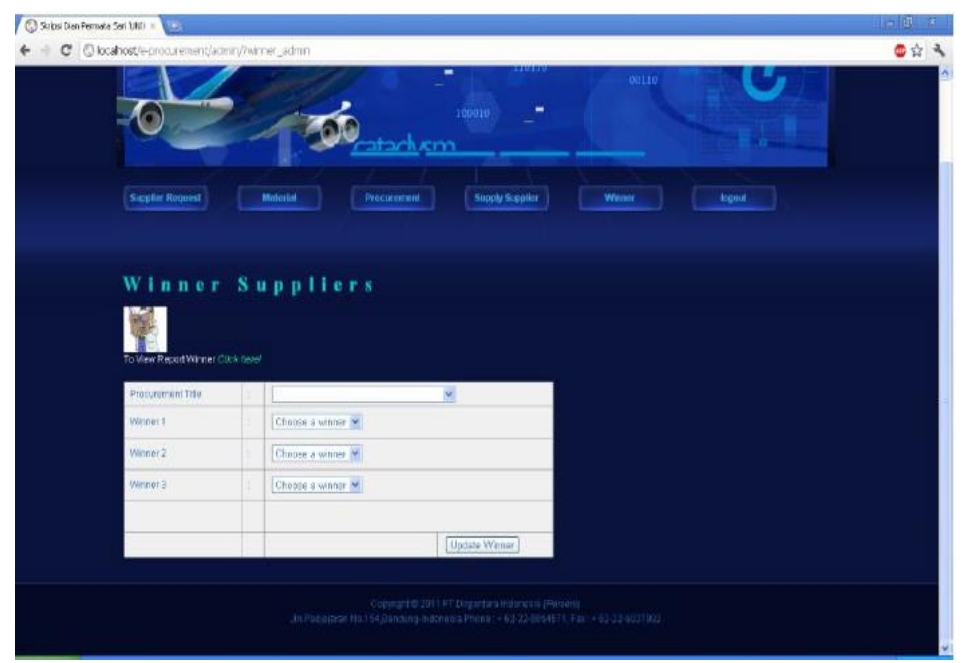

Gambar 10 Halaman memilih winner

9. Halaman view list winner untuk supplier untuk admin

Pada halaman ini merupakan halaman dari daftar pemenang yang telah di acc oleh perusahaan dan hanya dapat diakses oleh pihak perusahaan.

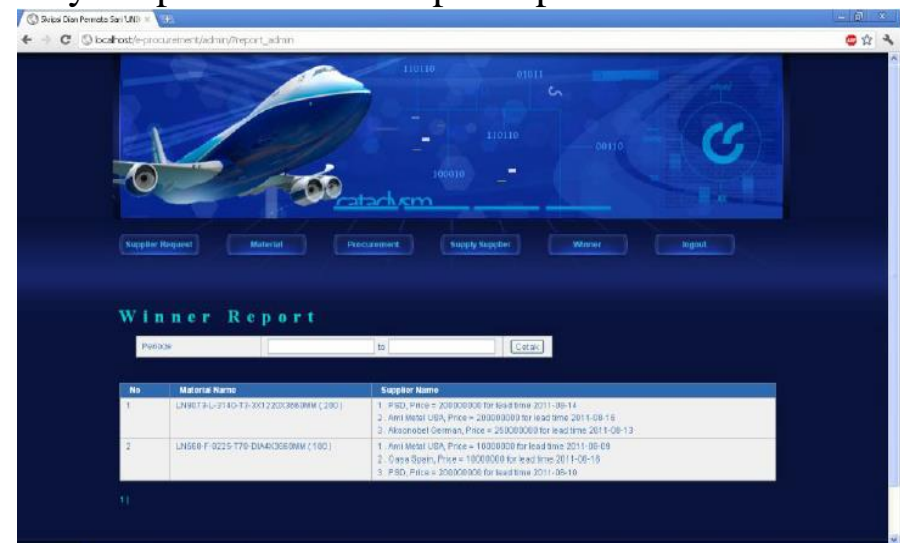

Gambar 11 view list winner supplier

10. Halaman informasi winner kepada supplier

Pada halaman informasi winner ini merupakan halaman bagi anggota yang mengajukan penawaran material pesawat pada perusahaan. Jika anggota terpilih oleh pihak perusahaan dalam mengajukan penawaran material, anggota akan diberi pemberitahuan pada halaman winner anggota. 


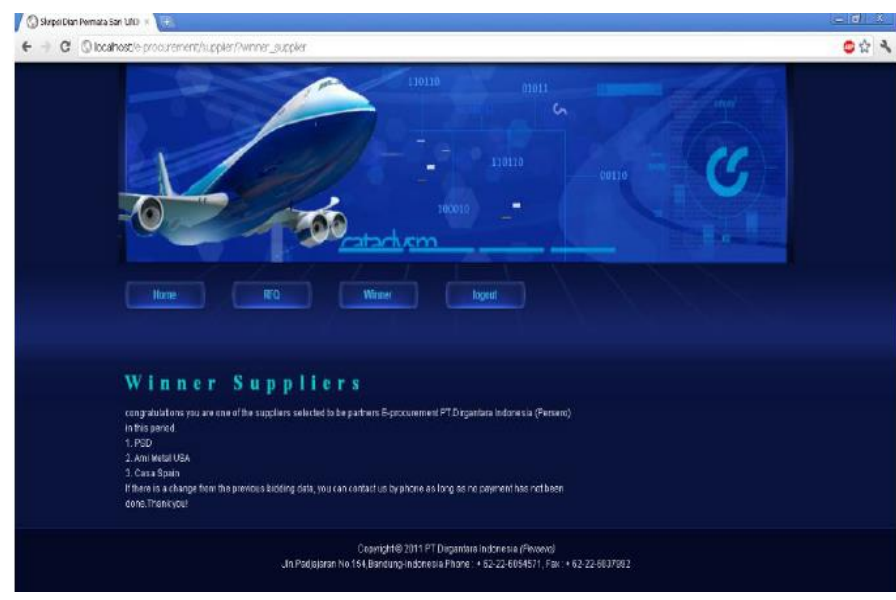

Gambar 12 Informasi winner kepada supplier

\section{KESIMPULAN}

Dengan adanya kemajuan teknologi dan internet pada saat ini, sudah menjadi kebutuhan pokok suatu perusahaan dalam melibatkan aktivitasnya untuk bergerak maju menyesuaikan kebutuhannya sehingga menjadikan manajemen dalam perusahaan menjadi lebih efektif dan efisien. Salah satu bentuk dari bentuk manajemen adalah adanya sistem informasi yang terintergrasi dalam pengelolaannya. Aplikasi ini dapat membantu perusahaan dalam mengelola e-procurement material pesawat.

\section{DAFTAR PUSTAKA}

[1] Rizky, Soetam. 2011. Konsep Dasar Rekayasa Perangkat Lunak dan Software Reengineering. PT.Pestasi Pustakaraya: Jakarta. pg 135

[2] Davila, A., Gupta, M., \& Palmer, R. 2003. Moving procurement systems to the internet: The adoption and use of e-procurement technology models. European management journal, 21(1), pg 11-23

[3] Setiyani, R. 2010. Pemanfaatan Internet Sebagai Sumber Belajar. Dinamika Pendidikan, 5(2)

[4] Sugiarto, dkk. 2001. Teknik Sampling. Jakarta: PT Gramedia Pustaka Utama.

[5] Mulyanto, Agus. 2009. Sistem Informasi Konsep \& Aplikasi. Pustaka Pelajar: Yogyakarta.

[6] Kadir, Abdul. 2009. From Zero To A Pro Membuat Aplikasi Web Dengan PHP + Database MYSQL. ANDI OFFSET: Yogyakarta. 